\title{
Temperatura superficial y estado de la vegetación del bosque de Polylepis spp, distrito de San Marcos de Rocchac, Huancavelica - Perú
}

\author{
(Surface temperature and states of the vegetation \\ of the forest of Polylepis spp, district of San Marcos \\ de Rocchac, Huancavelica - Peru)
}

Quispe Reymundo Bimael J. ${ }^{1}$, Révolo Acevedo Ronald H. ${ }^{2}$

\begin{abstract}
Resumen
El efecto de la temperatura superficial sobre el estado de la vegetación en el bosque de Polylepis spp es el objetivo de esta investigación. Como metodología se utilizó 9 imágenes satelitales del Sensor Landsat 8 OLI/TIRS, evaluadas mediante la percepción remota, aplicando correlación $r$ Pearson e hipótesis estadística t student. Como resultado se obtuvieron las relaciones durante los 9 meses del año 2018 - 2019 entre LST - NDVI r=0.11, t=0.29; LST - NDWI r=-0.43, t=1.27; LST - SAVI r=0.13, t=0.34 y LST - MSI r=0.56, t=1.77; la relación promedio de 9 imágenes clasificado en valores Jenks Natural Breaks entre LST - NDVI r=0.99, $\mathrm{t}=47.12 ;$ LST - NDWI $r=-0.98, \mathrm{t}=28.93 ; \mathrm{LST}-\mathrm{SAVI} \mathrm{r}=-0.99, \mathrm{t}=65.39$ y LST $-\mathrm{MSI} \mathrm{r}=0.99$, $\mathrm{t}=30.39$; $y$ el efecto del "TVX" para NDVI(Este:-0.0778/0.0549; Oeste:0.6434/-0.0120), NDWI(Oeste:-0.6128/-0.0463; Este:0.3057/0.0474), SAVI (Oeste:0.4089/0.0232; Este:-0.0073/-0.0011) y MSI(Este:0.5565/0.1856; Oeste:1.3993/ 0.0362). En conclusión, se confirma que en los 9 meses que duró el monitoreo no existió correlación estadística pero que en promedio de las 9 imágenes clasificados en Jenks Natural Breaks sí existe correlación; TVX confirmó la influencia de temperatura superficial sobre el estado de vegetación dentro del bosque a través del tiempo.
\end{abstract}

Palabras clave

Polylepis; LST; Estado de la Vegetación; TVX; Jenks Natural Breaks.

\begin{abstract}
The effect of surface temperature on the state of the vegetation in the forest of Polylepis spp and to relate it is the objective of this research. As methodology 9 satellite images of the Landsat 8 OLI / TIRS Sensor were used, evaluated using remote sensing, applying Pearson r correlation and statistical t student hypothesis. The following results were obtained: the relationships during the 9 months of the year $2018--2019$ between LST $-N D V I r=0.11, t=0.29$; $L S T-N D W I r=-0.43, t=1.27$; LST - SAVI $r=0.13, t=0.34$ and $L S T-M S I r=0.56, t=1.77$; the average ratio of 9 images classified in Jenks Natural Breaks values between LST - NDVI $r=0.99, t=47.12 ;$ LST - NDWI $r=-0.98, t=28.93 ;$ LST - SAVI $r=-0.99, t=65.39$ and LST - MSI $r=0.99, t=30.39$; and the effect of "TVX" for NDVI (East: $-0.0778 / 0.0549$; West: 0.6434 / -0.0120), NDWI (West: -0.6128/-0.0463; East: 0.3057 / 0.0474), SAVI (West: 0.4089 / 0.0232; East: -0.0073 / -0.0011) and MSI (East: 0.5565 / 0.1856; West: 1.3993/0.0362). In conclusion, it is confirmed that during the 9 months that the monitoring lasted, there was no statistical correlation and that on average of the 9 images classified in Jenks Natural Breaks there is a correlation; TVX confirmed the influence of surface temperature on the state of vegetation within the forest over time.
\end{abstract}

Keywords

Polylepis; LST; Vegetation States; TVX; Jenks Natural Breaks

\section{Introducción}

Los bosques de Polylepis representan una columna de existencia y supervivencia para la flora y fauna nativa del Perú. Su importancia es tanto ecológica como humana (Fjeldså, 1993; Hoch yy

$1 \quad$ Ciencias Forestales y del Ambiente - UNCP, Huancayo - Perú (bjgrforesambagmail.com).

2 Ciencias Forestales y del Ambiente - UNCP, Huancayo - Perú (rrevolo@uncp.edu.pe). 
Körner, 2005; Kessler, 2006). Estos bosques se encuentran ubicados cerca de áreas con neblinas (Hoch y Körner, 2005), zona áridas (Dourojeanni P., 2008), laderas pedregosas y pendientes empinadas (Fjeldså, 1993; Segovia-Salcedo, Domic, Boza, y Kessler, 2018), asociadas con musgos, líquenes y plantas epifitas (Hoch y Körner, 2005; Kessler, 2006). Existen pocos estudios que evalúan los bosques de Polylepis mediante el uso de las imágenes satelitales (Landsat) (Braun, 1997; Campomanes, 2017; Contreras, 2019; Dourojeanni P., 2008; Mejia Rios, 2014; Pacheco, Franco, Cáceres, Navarro, y Jove, 2018; Zutta et al., 2012) Uno de los primeros es Braun ( 1997), que evalúa las características ambientales, estado vegetal y ecológico utilizando imágenes Landsat en bosque de Polylepis tarapacana.

El "Estado de la Vegetación" mencionado por Alshaikh, 2015, Anbazhagan y Paramasivam (2016); Gilabert, González-Piqueras, y García-Haro (1997) y Muñoz (2013) busca evaluar cuantitativa/cualitativa, (Campomanes, 2017; Ito et al., 2007) y describir su medio ambiente vegetal (Contreras, 2019; Gonzaga, 2015; Ito et al., 2007) por medio de imágenes Landsat, mediante los índices de vegetación, (Gilabert et al., 1997; Ito et al., 2007; Weng, Lu, y Schubring, 2004), determinando la densidad, estrés hídrico, estado sanitario y la influencia de la temperatura (Alshaikh, 2015; Anbazhagan y Paramasivam, 2016; Carvajal y Pabón, 2014; Galvão, Formaggio, y Tisot, 2005; Gilabert et al., 1997). Los índices de vegetación son transformaciones que implican efectuar una combinación matemática entre los niveles digitales almacenados en dos o más bandas espectrales de la misma imagen (Gilabert et al., 1997; Gonzaga, 2014; Speranza y Zerda, 2002).

El NDVI determina el verdor y vigor, y la densidad de biomasa de las cubiertas vegetales (Rouse, Hass, Schell, y Deering, 1973; Silva Laurentino, 2014; Weng et al., 2004) indicando la salud de las masa forestales y estado de fitosanidad (Jepsen et al., 2009; Silva Laurentino, 2014); el NDWI se utilizó en estudios forestales (Ito et al., 2007; Stimson, Breshears, Ustin, y Kefauver, 2005), el cual indica el agua que posee la vegetación o el nivel de saturación de humedad que posee el suelo (Almeida, 2015), así como el contenido de humedad interno de la vegetación (Galvão et al., 2005); diferenciando la humedad del suelo de la densidad y cobertura del suelo (Campomanes, 2017); el SAVI minimiza el efecto del suelo en áreas con baja cobertura o baja densidad vegetal (Gilabert et al., 1997; Huete, 1988) y porcentaje de cubierta vegetal (Jepsen et al., 2009); en orientaciones y zona altitudinal en estos bosque determina su densidad, en relación con el suelo desnudo (Campomanes, 2017; Dourojeanni P., 2008; Mejia Rios, 2014; Pacheco et al., 2018), la mayor densidad de Polylepis se ubica en 4400 - 4500 m.s.n.m. (Braun, 1997; Dourojeanni P., 2008); y, por último, el MSI, la cual es utilizado para conocer el estrés de una cobertura vegetal (Hardisky, Klemas, y Smart, 1983), relacionando con la temperatura de la planta y la humedad aprovechable del suelo (Silva Laurentino, 2014); relacionando a la humedad del suelo, precipitación y la temperatura (Hong, Lakshmi, y Small, 2007).

La temperatura superficial controla el intercambio de calor y agua superficial con la atmosfera; el uso/cobertura del suelo es un factor importante que tiene un impacto sobre el ecosistema (Alshaikh, 2015; Anbazhagan y Paramasivam, 2016); la interacción entre la temperatura y la vegetación diferencia el tipo de cobertura del suelo y su estado (De Sousa y Júnior, 2012; Gonzaga, 2014; Weng et al., 2004), así como el potencial de sequía y efecto hacia las plantas (Goward et al., 1994; Orhan, Ekercin, y Dadaser-Celik, 2014). Este análisis es conocido como Índice Temperatura - Vegetación (Goward et al., 1994). La temperatura tiene influencia en las características de la vegetación (Campomanes, 2017; Carvajal y Pabón, 2014; Hong et al., 2007): si aumenta la cubierta vegetal, la temperatura descenderá (Alshaikh, 2015; Anbazhagan y Paramasivam, 2016; De Sousa y Júnior, 2012). En otras palabras, si existen variaciones térmicas a través del tiempo, 
la densidad de la cobertura vegetal se transformará cambiando así su estado vegetal (Alshaikh, 2015; Anbazhagan y Paramasivam, 2016; Campomanes, 2017; Orhan et al., 2014).

No existen estudios que evalúen la influencia y la relación de la temperatura a través del tiempo sobre el bosque de Polylepis mediante imágenes satelitales Landsat, lo cual es importante (De Sousa y Júnior, 2012; Goward et al., 1994; Orhan et al., 2014; Weng et al., 2004) para observar el estado de vegetación por el efecto de la temperatura (Goward et al., 1994; Weng et al., 2004). La investigación implica relacionar la temperatura superficial y los índices de vegetación durante los 9 meses del año 2018 - 2019, con un promedio de 9 imágenes clasificadas en 20 valores naturales y, finalmente, analizar la influencia de la temperatura sobre el estado de la vegetación del bosque de Polylepis.

\section{Metodología}

\section{A. Área de estudio}

El bosque de Polylepis spp se localiza en el distrito de San Marcos de Rocchac en la provincia de

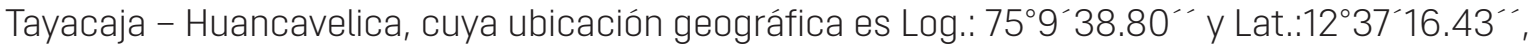
a unos 3800 - 4500 m.s.n.m., con una extensión de 56.2639 Ha.

Figura 1. Mosaico bandas espectrales 6,5 y 4 "Análisis de Vegetación", Polylepis (limite rojo)
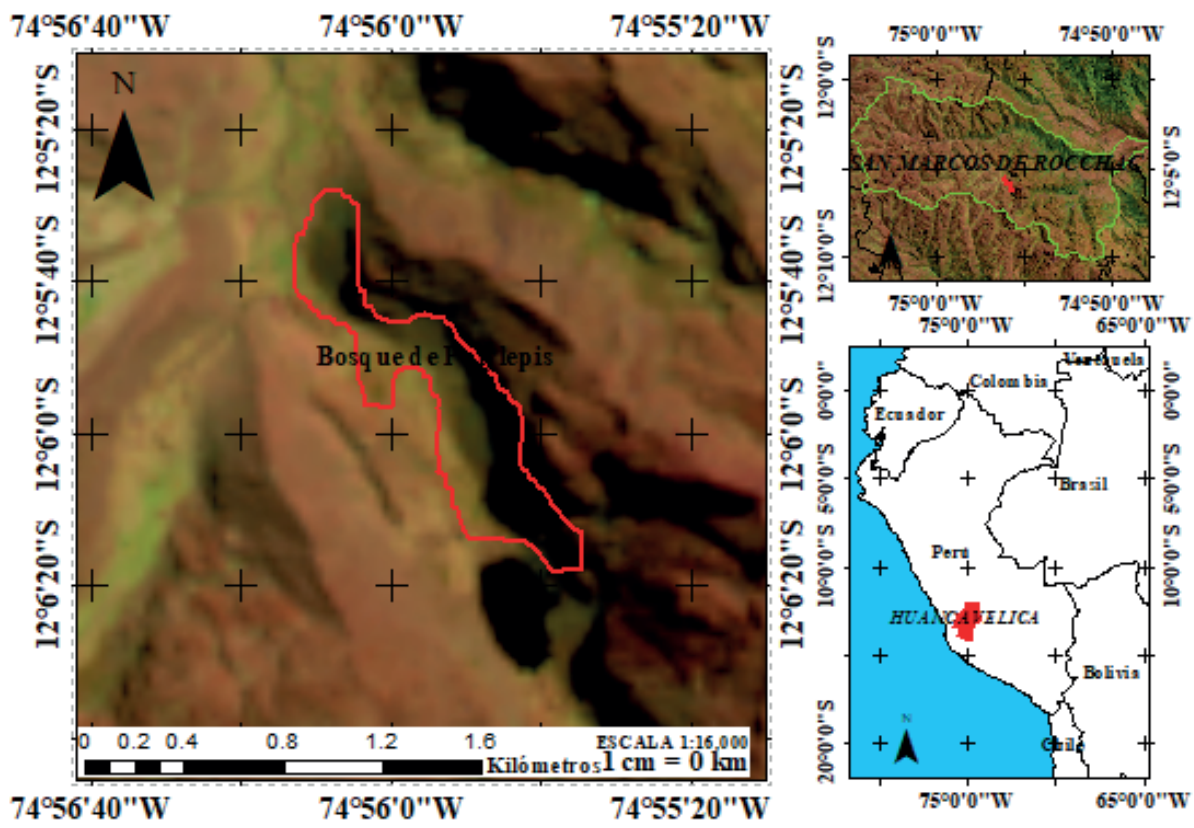

\section{B. Obtención de imágenes satelitales}

Se utilizó 9 imágenes satelitales Landsat 8 OLI/TIRS, tomadas durante los años 2018 y 2019; con cubierta de nubes terrestre 50 \%, georreferenciación Path 6 y Row 68 extraído del Servicio Geológico de Estados Unidos (USGS) cuyo sitio web es https://earthexplorer.usgs.gov/ 


\section{Temperatura Superficial Terrestre (LST)}

\section{CoRRECCIÓN DE BANDA ESPECTRAL}

Resplandor de la parte superior de la atmósfera (TOA), datos del texto (_MTL.txt) (Anandababu, Purushothaman, y Suresh Babu, 2018; Bravo, 2017; USGS, 2019).

$$
L_{\lambda}=(M L)^{*}(Q c a l)+A L
$$

Donde:

$L \lambda$ : radiancia espectral TOA (Watts/(m2* $\left.{ }^{*}{ }^{*} \mu \mathrm{m}\right)$.

ML: banda multiplicativa de resplandor (Radiancia_Mult_Band_X, x: número de la banda).

AL: agregar resplandor de banda (Radiancia_Mutl_Band_X_X: número de banda).

Qcal: valor de pixel de productos estándar cuantificados y calibrados.

Temperatura de brillo de la parte superior de la atmósfera: datos de (_MTL.txt). (Anandababu et al., 2018; Bravo, 2017; USGS, 2019).

$$
T_{b}=\frac{K_{2}}{\ln \left(\frac{K_{1}}{L_{\lambda}}+1\right)}-272.15
$$

Donde:

Tb: temperatura de brillo de la parte superior de la atmosfera $\left({ }^{\circ} \mathrm{C}\right)$.

$L \lambda$ : radiancia espectral TOA. K1: K1 constante de la banda (_MTL.txt: número de banda).

K2: k2 constante de la banda (_MTL.txt: número de banda)

Emasividad de la superficie terrestre: calculada por valores de NDVI. Cálculo de la proporción de la vegetación (Anandababu et al., 2018).

$$
P_{v}=\left(\frac{N D V I-N D V I_{\min }}{N D V I_{\max }-N D V I_{\min }}\right)^{2}
$$

Donde:

PV: proporción de la vegetación

NDVI: índice de vegetación de diferencia normalizada

NDVI (max. - min.): valores máximos y mínimos de NDVI.

Cálculo de la Emasividad (Anandababu et al., 2018).

$$
\varepsilon=0.004 * P_{v}+0.986
$$

Donde:

$\varepsilon$ : emasividad de la superficie terrestre.

PV: proporción de la vegetación

Ecuación general de la temperatura superficial terrestre (Anandababu et al., 2018; Carnahan y Larson, 1990).

$$
L S T=\frac{T_{S}}{1+\ln \varepsilon^{*}\left(\frac{T_{S}{ }^{*} W}{14380}\right)}
$$


Donde:

Bt: temperatura de brillo de la parte superior de la atmósfera $\left({ }^{\circ} \mathrm{C}\right)$.

W: longitud de onda de Radiancia emitida.

$\varepsilon$ : emasividad de la superficie terrestre.

\section{Estimación de los Índices de Vegetación}

\section{CorRECción de bandAs ESPECTRALES}

Determinación de reflectancia aparente (TOA) y conversión de los niveles digitales a valores de reflectancia, (_MTL.txt) (Bravo, 2017; USGS, 2019).

$$
\rho_{\lambda}=\frac{M_{\rho}^{*} Q_{c a l}+A_{\rho}}{\cos \left(\theta_{Z E}\right)}
$$

Donde:

$\rho \lambda$ : reflectancia TOA del sensor, con corrección del ángulo solar. Qcal: valor de pixel producto estándar cuantificado y calibrado (ND).

M $\rho$ : factor de cambio de escala multiplicativo (Reflectance_Mult_Band_X, X: número de banda).

A $\rho$ : banda específico aditivo reescala factor de los metadatos (Reflectance_Add_Band_X, X: número de banda).

$\theta_{\mathrm{ZE}}$ : ángulo de elevación del sol local (Sun_Elevation). Equivalente a 90- $\theta_{\mathrm{ZE} \mathrm{Z}^{\prime}}$ donde $\theta_{\mathrm{ZE}}$ es la elevación solar.

\section{ECUACIÓN PARA BANDAS ESPECTRALES}

El índice de vegetación de diferencia normalizada (NDVI) determina el vigor de la vegetación, biomasa vegetal sin presencia de enfermedades (Rouse et al., 1973) y estado fitosanitario (Silva Laurentino, 2014); los valores digitales se encuentran entre -1 a 1, donde 1 demuestra un buen vigor de la vegetación.

$$
N D V I=\frac{N I R-R}{N I R+R}
$$

Donde:

NIR es reflectancia de la banda infrarroja cercano (banda 5).

$\mathrm{R}$ es reflectancia de la banda roja (banda 4).

El índice de agua de diferencia normalizada (NDWI) analiza el contenido de humedad en las plantas y contenido de agua que posee el suelo; los valores se encuentran entre -1 a 1; donde 1 es el contenido de agua abundante y -1 lo inverso (Hardisky et al., 1983).

$$
N D W I=\frac{G-N I R}{G+N I R}
$$

Donde:

G: reflectancia de la banda verde (banda 4)

NIR: reflectancia de la banda infrarroja cercano (banda 5). 
El índice ajustado a la vegetación del suelo (SAVI) determina la erosión del suelo en relación con la densidad de la vegetación (Gonzaga, 2014; Huete, 1988); el valor se encuentran entre -1 a 1, el valor 1 representa excesiva erosión y - 1 todo lo contradictorio.

$$
S A V I=\left(\frac{N I R-R}{N I R+R+1}\right) *(1+L)
$$

Dónde:

NIR: reflectancia de la banda infrarroja cercano (banda 5),

R: reflectancia de la banda roja (banda 4)

L: (densidad: 0.00 u 0.25 cubierta vegetal, 0.5 cobertura de vegetación medio y 1 cubierta de vegetación baja).

El índice de estrés hídrico (MSI) determina el estrés hídrico o déficit hídrico de la cobertura vegetal; estos valores oscilan entre -3 a 3. El valor 3 obtendrá un mayor estrés hídrico de la cobertura vegetal (Rock, Vogelmann, Williams, Vogelmann, y Hoshizaki, 1986).

$$
M S I=\frac{S W I R}{N I R}
$$

Donde:

SWIR: reflectancia de la banda infrarroja medio (banda 6)

NIR: reflectancia de la banda cercano (banda 5).

\section{E. Clasificación de estándares, Análisis de correlación e hipótesis estadístico}

La clasificación estándar se realizó mediante el método de "Jenks Natural Breaks 1967", diseñando intervalos de clases naturales y estableciendo agrupaciones inherentes a los datos (Smith, Goodchild, y Longley, 2018); mediante el QGis 3.10.1; relación lineal $r$ Pearson e hipótesis estadística t student con $\alpha=0.05$ se realizó con el programa $R$ studio.

\section{F. Índice Temperatura - Vegetación (TVX)}

Determina la relación entre la temperatura superficial y el índice de vegetación (potencial efecto/sequia de las plantas) (Goward et al., 1994), comparando el resultado de los índices de vegetación mediante los valores digitales de la imagen Landsat 8 OLI/TIRS.

$$
T V X=\frac{s V I}{L S T}
$$

Donde:

LST: temperatura superficial terrestre

sVl: índice de vegetación espectral.

\section{Resultados}

\section{A. Temperatura Superficial Terrestre (LST)}

La Tabla 1 muestra la temperatura mínima registrada con las imágenes satelitales. Como se puede observar, durante los 9 meses del año 2018 - 2019 la temperatura es de $4.79^{\circ} \mathrm{C}$, que corresponde a la fecha (23/04/19), y la máxima temperatura es $30.64^{\circ} \mathrm{C}$, con fecha $(13 / 10 / 18)$. La temperatura 
superficial terrestre promedio de las 9 imágenes satelitales clasificados en 20 valores naturales encontró valor mínimo de $6.66^{\circ} \mathrm{C}$ y temperatura máxima de $26.35^{\circ} \mathrm{C}$ (Figura 2.a y b).

Figura 2. Imagen a) LST promedio de 9 imágenes durante el año 2018 - 2019;

b) promedio de 9 imágenes clasificadas en 20 Jenks Natural Breaks. Tamaño de pixel 30X30m aplicando técnica de remuestreo de visualización interpolación bilineal (proporcionando resultado de aspecto suavizado)

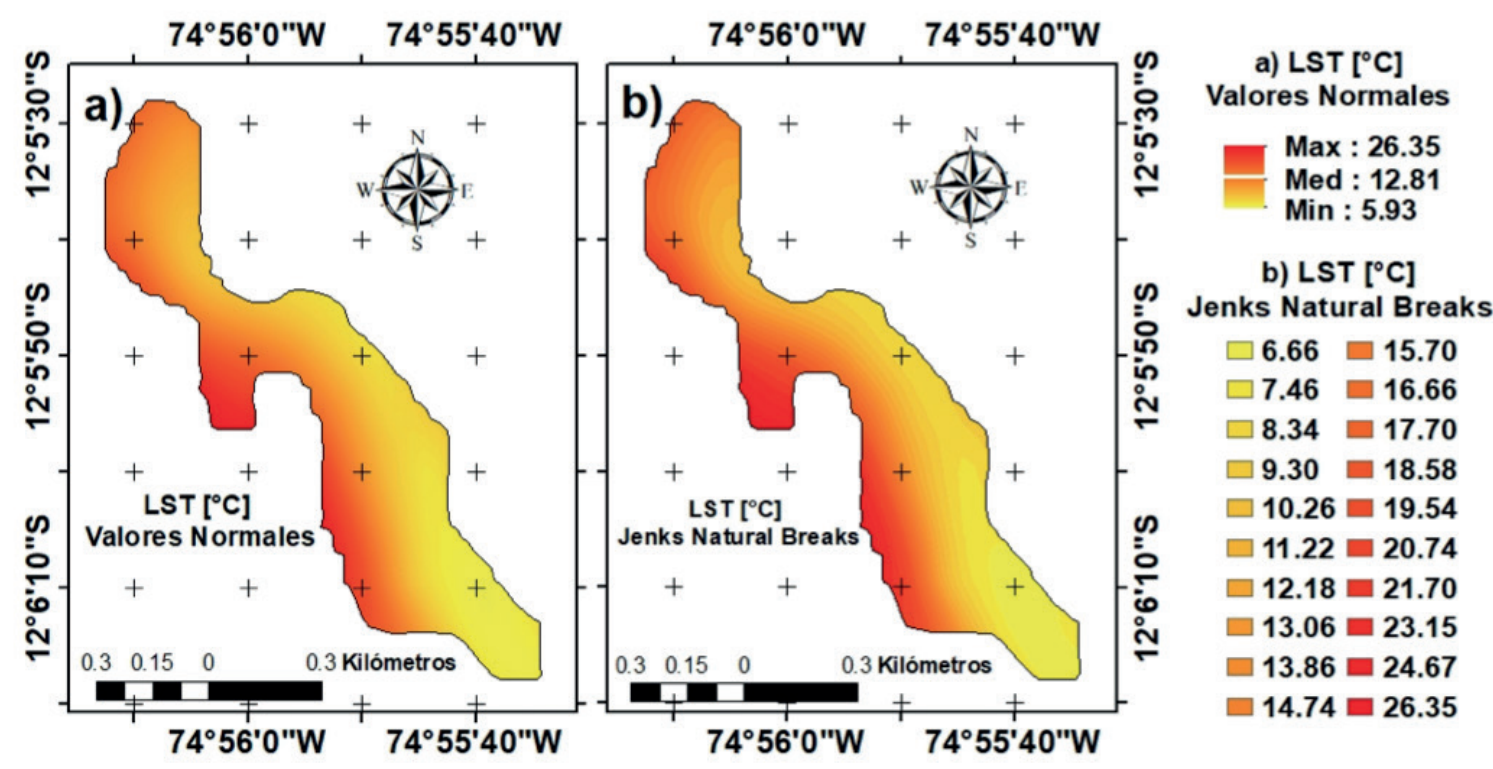

\section{B. NDVI, NDWI, SAVI y MSI durante los 9 meses entre el 2018 y 2019}

El NDVI máximo, durante los 9 meses de monitoreo, fue de 0.6937, lo cual se considera un muy buen estado fitosanitario, correspondiendo a la fecha 01/01/19. Este valor se encuentra en los rangos establecidos de los valores NDVl; el valor mínimo durante los 9 meses es -0.3220, presentando en mal estado fitosanitario y corresponde a la fecha 23/04/19.

Tanto el mínimo como el máximo valor corresponden a la fecha 23/04/09 del NDWI con 0.8318 , indicando un alto contenido de humedad o contenido de agua, y el valor mínimo es -0.6642, indicando un bajo contenido de agua o humedad.

El SAVI dentro del bosque de Polylepis indicó un valor máximo de 0.5037, obtenido así alta erosión y bajo contenido de Polylepis, en la fecha 01/01/19, y un valor mínimo de -0.0406, indicando así un bajo contenido de erosión y una abundancia de Polylepis, correspondiendo a la fecha 23/04/19.

El MSI registró un valor mínimo de 0.5355, presentando un contenido de agua moderado, el cual corresponde a la fecha 23/04/19, y el valor máximo es 1.7320, siendo un estrés hídrico alto de la cobertura vegetal; es decir, el contenido de agua del tejido o célula vegetal está abajo del contenido de agua más alto, y corresponde al 07/06/18. 
Tabla 1. Resultado de valores digitales del bosque de Polylepis spp

\begin{tabular}{|c|c|c|c|c|c|c|c|c|c|c|}
\hline \multirow{2}{*}{ Fecha } & \multicolumn{2}{|c|}{ NDVI } & \multicolumn{2}{c|}{ SAVI } & \multicolumn{2}{c|}{ NDWI } & \multicolumn{2}{c|}{ MSI } & \multicolumn{2}{c|}{ LST } \\
\cline { 2 - 11 } & $\min$ & $\max$ & $\min$ & $\max$ & $\min$ & $\max$ & $\min$ & $\max$ & $\min$ & $\max$ \\
\hline $22 / 05 / 2018$ & -0.0468 & 0.6543 & -0.0059 & 0.4129 & -0.6262 & 0.2541 & 0.3772 & 1.4068 & 6.97 & 28.37 \\
\hline $07 / 06 / 2018$ & 0.0472 & 0.6455 & -0.0117 & 0.3839 & -0.6197 & 0.3090 & 0.4172 & 1.7320 & 5.85 & 25.98 \\
\hline $23 / 06 / 2018$ & -0.0984 & 0.6568 & -0.0089 & 0.4260 & -0.6390 & 0.3477 & 0.5355 & 1.4974 & 5.05 & 28.19 \\
\hline $13 / 10 / 2018$ & 0.0308 & 0.6601 & -0.0035 & 0.4238 & -0.6258 & 0.2538 & 0.5149 & 1.4833 & 6.70 & 30.64 \\
\hline $01 / 01 / 2019$ & 0.1401 & 0.6937 & -0.0159 & 0.5037 & -0.6607 & 0.3607 & 0.4540 & 1.3411 & 6.47 & 22.26 \\
\hline $23 / 04 / 2019$ & -0.3220 & 0.6750 & -0.0407 & 0.4733 & -0.6642 & 0.8318 & 0.3133 & 1.5707 & 4.79 & 23.81 \\
\hline $25 / 05 / 2019$ & 0.2039 & 0.6680 & -0.0177 & 0.4408 & -0.6438 & 0.4301 & 0.3786 & 1.5916 & 5.15 & 24.37 \\
\hline $26 / 06 / 2019$ & 0.0273 & 0.6275 & 0.0040 & 0.4031 & -0.6023 & 0.1611 & 0.5241 & 1.4191 & 5.05 & 25.73 \\
\hline $12 / 07 / 2019$ & -0.0700 & 0.6254 & -0.0072 & 0.3787 & -0.6072 & 0.3051 & 0.5348 & 1.4976 & 5.84 & 29.90 \\
\hline
\end{tabular}

Resultados máximos y mínimos de valores digitales durante 9 meses del año 2018 - 2019.

Figura 3. Análisis del bosque de Polylepis spp mediante los valores mínimos y máximos de los índices de vegetación, durante 9 meses en el periodo 2018 - 2019. Figura: a) menciona el estado fitosanitario;

b) contenido de agua; c) erosión del suelo; y d) estrés hídrico del bosque. Tamaño de celda/pixel 30×30m aplicando técnica de remuestreo de visualización interpolación bilineal

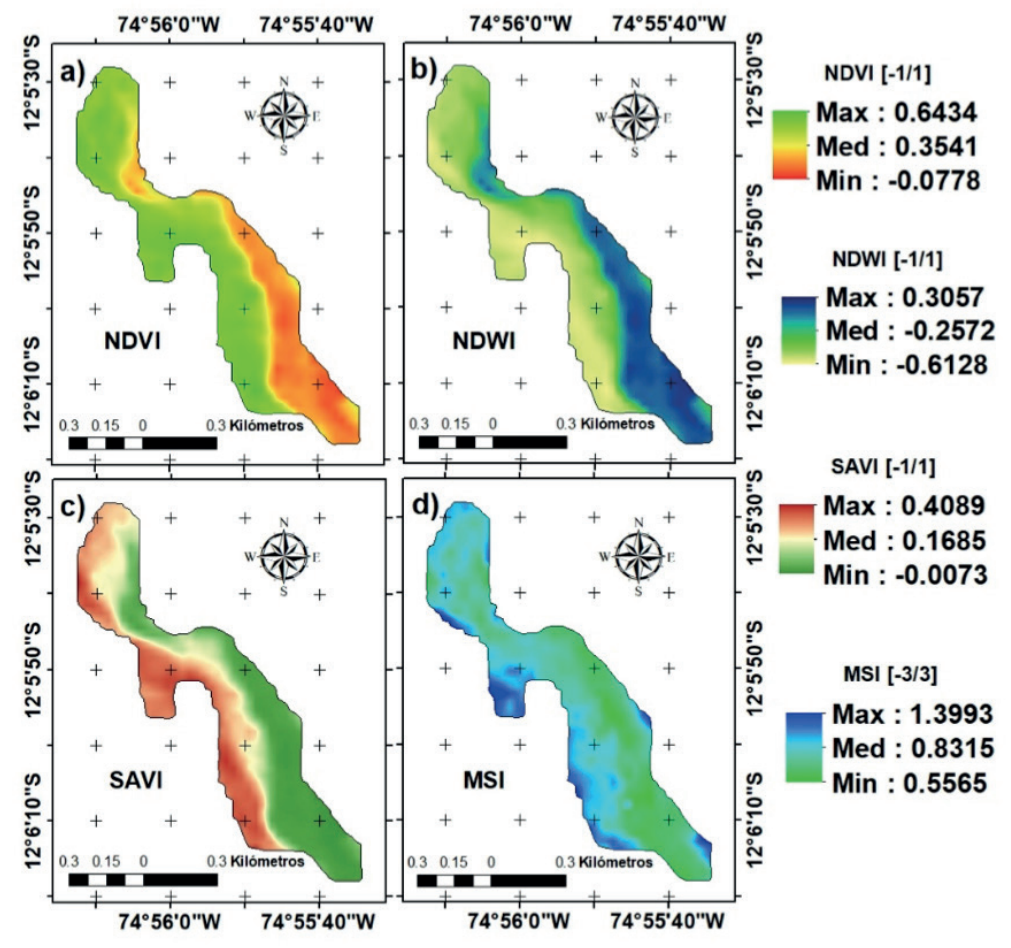

\section{NDVI, NDWI, SAVI y MSI promedio de las 9 imágenes satelitales clasificados en 20 valores naturales}

El valor mínimo del NDVI es 0.0013 ubicado en la orientación Este, y valor máximo es 0.6434 Oeste. Estos valores demostraron que la vegetación está en media-alto estado fitosanitario; el 
valor 0.6434 indica que el bosque de Polylepis está en un buen estado fitosanitario y el valor mínimo no excede a 0 o -1, lo que indica que la vegetación está medianamente enferma, como se observa en la Figura 4, a).

El NDWI demostró un valor mínimo de -0.5768 indicando un bajo contenido de humedad o contenido de agua; este valor se encuentra identificado en la orientación Suroeste-y el valor máximo de 0.3057, indicando un contenido de humedad medio, está ubicado en la orientación Este, Figura 4, b). Cabe recordar que este valor no alcanzó a -1 y, en especial, a 1, ya que es un indicador del contenido de agua en el bosque de Polylepis.

En tanto los valores naturales del SAVI encontraron el máximo de 0.4089 , indicando que existe una erosión del suelo media con cobertura de vegetación casi nula, este valor se encuentra ubicado en la orientación Suroeste; y valor mínimo de 0.0106 indicando un contenido de erosión casi nulo y cobertura de vegetación media, se encuentra en la orientación Noreste, donde se confirma que estos valores clasificados naturalmente no alcanza a -1, cuyo indicador es primordial para determinar si el bosque no presenta nada de erosión y tiene una cobertura de vegetación alta. También se puede observar esto en la Figura 4, c).

El MSI mostró valor máximo de 1.3993, correspondiendo a un estrés hídrico medianamente alto; es decir, que el contenido de agua del tejido o célula vegetal está abajo del contenido de agua más alto, y el valor mínimo es 0.5961, mencionando que el estrés hídrico del bosque de Polylepis es moderado, como se observa en la Figura 4, d).

Figura 4. Análisis de mínimos y máximo de los índices de vegetación promedio de 9 imágenes clasificado en 20 valores Jenks Natural Breaks. Figura: a) estado fitosanitario; b) contenido de agua; c) erosión del suelo; y d) estrés hídrico. Tamaño de pixel/celda 30×30m (proporcionando un resultado más suavizado) aplicando técnica de remuestreo de visualización interpolación bilineal

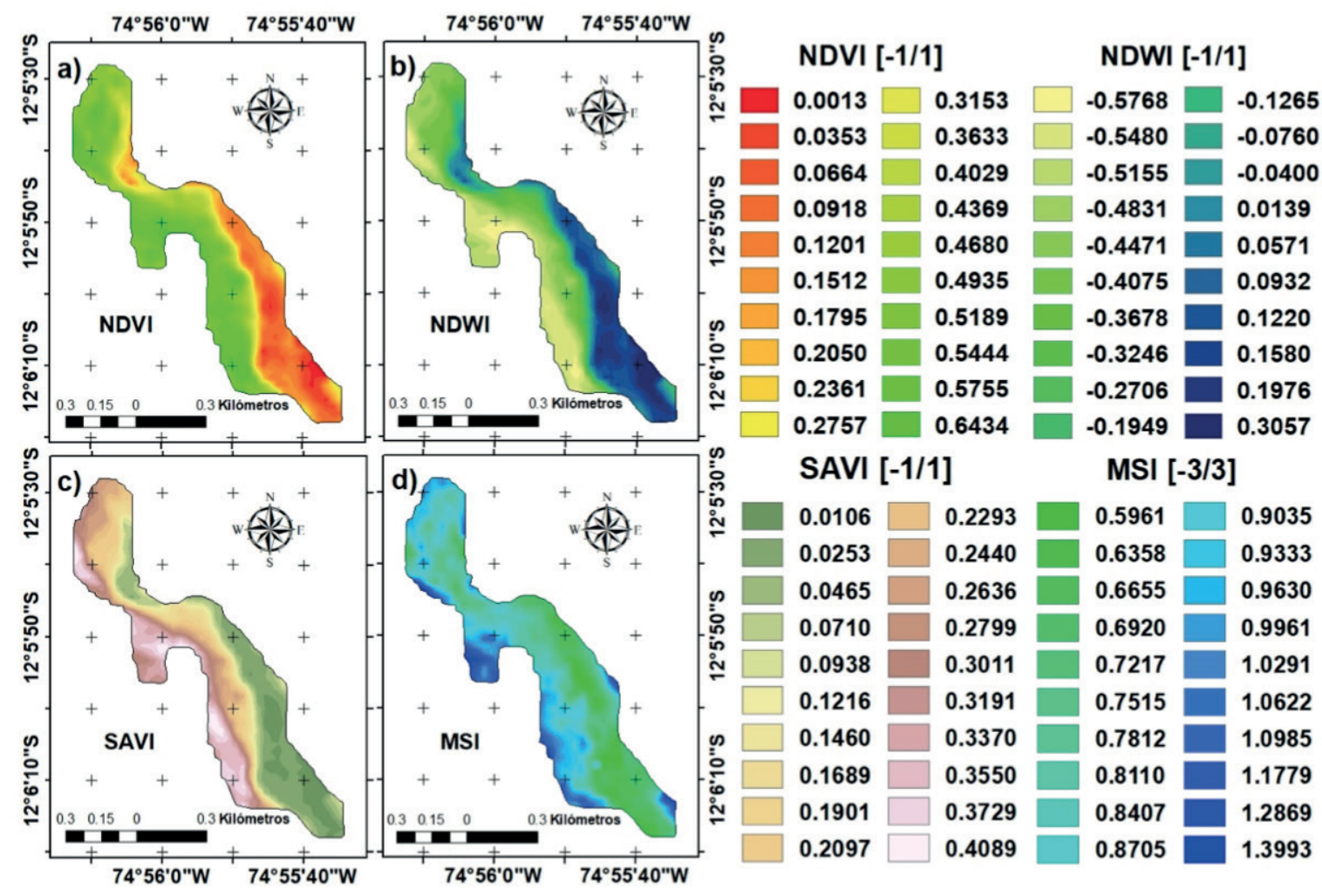




\section{Test de correlación}

\section{(LST - NDVI, NDWI, SAVI y MSI) DURANTE LOS 9 MESES DEL AÑo 2018 - 2019}

En la Figura 5 se muestra la correlación lineal Karl Pearson entre los 4 índices de vegetación y la temperatura superficial terrestre, contrastada con la prueba de hipótesis estadística t de student $(7 ; 0.05)=2.36$ bilateral, durante los 9 meses del periodo 2018 - 2019, demostró lo siguiente:

Para el NDVI - LST obtuvo un $r=0.11$, demostrando una correlación negativa muy baja, coeficiente de covariación cov = 0.01; contrastando con la hipótesis, la estadística t student resultó ser mayor al valor calculado en t $=0.29$ y $p$-valor $=0.78$.

La correlación entre NDWI - LST indicó un $r=-0.43$ siendo una correlación negativa moderada, coeficiente de covariación cov = -0.01; contrastada con la prueba estadística t de student demostró ser mayor al resultado calculado $t=1.27$ y $p$-valor $=0.24$.

La correlación SAVI - LST reveló un $r=0.13$, siendo una correlación positiva muy baja, con covariación cov = 0.01; aplicando la prueba t de student demostró ser muy alta al valor calculado con un $\mathrm{t}=0.34$ y $\mathrm{p}$-valor $=0.74$.

Y el test de correlación entre MSI - LST indicó un $r=0.56$, demostrando la existencia de una correlación positiva medianamente alta, covariación cov $=0.03$; contrapuesta con la prueba de hipótesis estadística t de student resultó ser mayor al valor calculado con $t=1.77$ y p-valor = 0.12; por lo tanto, se afirmó que no existe correlación lineal estadística alguna entre la temperatura superficial terrestre y los 4 indices de vegetación.

Figura 5. Correlación de la LST - NDVI, NDWI, SAVI, MSI durante los 9 meses del periodo 2018 - 2019. La figura a) es la relación entre LST - NDVI; b) relación entre LST - NDWI;

c) relación entre LST - SAVl; y d) la última relación entre LST - MSI
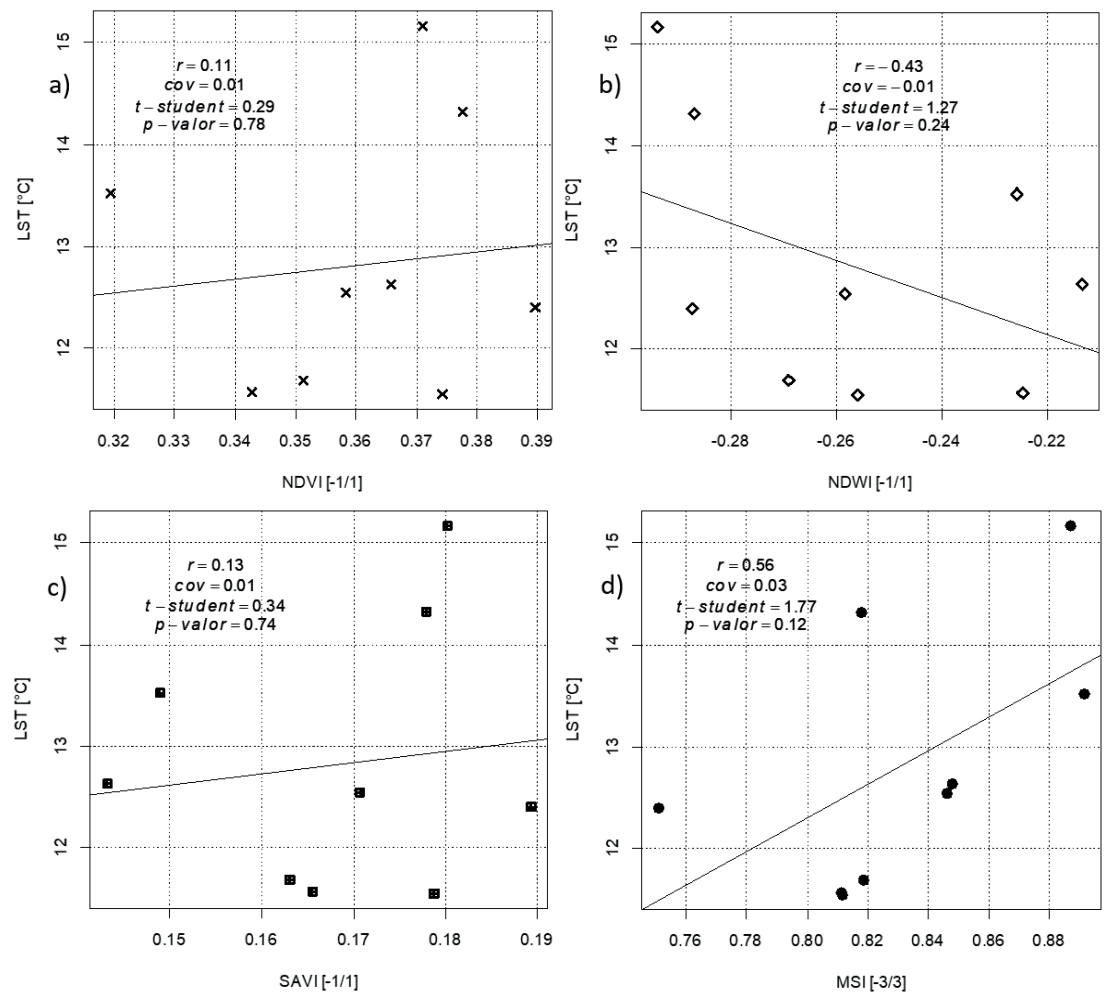


\section{(LST - NDVI, NDWI, SAVI, MSI) PROMEDIO DE LAS 9 IMÁGENES CLASIFICADO EN 20 VALORES NATURALES}

La correlación lineal entre la temperatura superficial terrestre y los cuatro índices de vegetación (Figura 6), promedio de las 9 imágenes satelitales clasificadas en 20 valores naturales, contrastada la prueba de hipótesis estadística t de student $(18 ; 0.05)=2.10$ bilateral, manifestó lo siguiente:

La correlación lineal entre NDVI - LST es de $r=0.99$, demostrando que, sí existe correlación positiva muy alta, con covariación cov = 1.09; contrastando con la prueba estadística t student resultó ser menor al resultado obtenido $t=47.12$ y p-valor $=2.2 \mathrm{e}-16$.

En la correlación NDWI - LST se obtuvo un $r=-0.98$, siendo una correlación negativa muy fuerte, covariación cov = 1.54; aplicando la hipótesis estadística t student resultó ser muy menor al valor calculado $t=28.93$ y $p$-valor $=2.2 \mathrm{e}-16$.

La correlación lineal de SAVI - LST tiene un $r=-0.99$, correlación negativa muy alta, covariación cov $=-0.68$, la cual fue destacada con la prueba de hipótesis estadística t student y resultó ser menor al valor calcula de t $=65.39$ y p-valor $=2.2 \mathrm{e}-16$.

La correlación entre MSI - LST mostró un $r=0.99$ siendo una correlación positiva muy alta, covariación cov = 1.21; aplicando la prueba de hipótesis t student correspondió ser menor al valor calculado $t=30.39$ y p-valor = 2.2e-16 (figura 6); consiguientemente, se afirmó que sí existe correlación lineal estadística altamente significativa entre los índices de vegetación y la temperatura superficial terrestre.

Figura 6. Correlación entre LST - NDVI, NDWI, SAVI, MSI, promedio de las 9 imágenes satelitales clasificado en 20 Jenks Natural Breaks. Los valores digitales se encuentran entre los rangos mínimos y máximos respecto a los intervalos de los índices, como también el LST mínimo a máximo
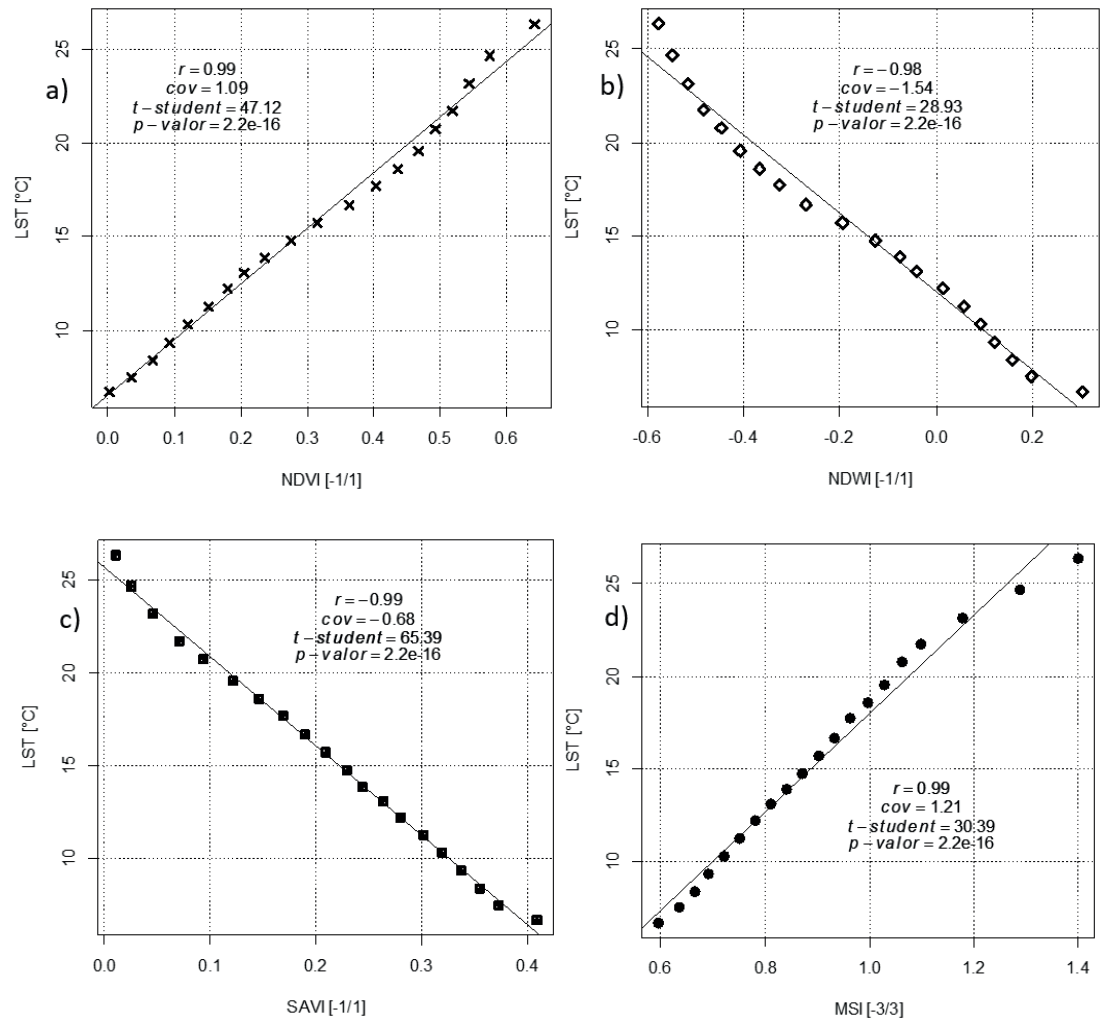


\section{E. Índice Temperatura - Vegetación (TVX)}

El efecto entre NDVI/LST determinó la influencia en el vigor de la biomasa fitosanitaria de la vegetación, aumentando en la orientación ESTE (-0.0778/0.0549) y disminuyendo en la orientación Oeste (0.6434/-0.0120) y creando un efecto de borde de (0.3541/0.0260), disminuyendo el estado fitosanitario del bosque.

Asimismo, en el efecto del NDWI/LST la temperatura influenció en el contenido de humedad o contenido de agua dentro del bosque, aumentó en la orientación Oeste (-0.6128/-0.0463), descendiendo en la orientación Este (0.3057/0.0474) y creando un efecto de borde (-0.2572/0.0139), incrementando contenido de agua dentro del bosque.

Por otro lado, el efecto del SAVI/LST determinó la influencia de la temperatura sobre la cobertura de la vegetación respecto al suelo en la orientación Oeste (0.4089/0.0232); la cobertura vegetal aumentó, en la orientación Este (-0.0073/-0.0011) la cobertura disminuye, creando un efecto de borde mínimo (0.1685/0.0110). Y el efecto del MSI/LST influenció en el estrés hídrico o déficit hídrico, disminuyendo en ambas orientaciones Este (0.5565/0.1856), Oeste (1.3993/0.0362), como también en el efecto de borde (0.8315/0.0725); por lo tanto, afirmamos que la temperatura influye en el vigor de la biomasa fitosanidad, contenido de humedad o contenido de agua, la cobertura vegetal respecto al suelo y estrés o déficit hídrico a través del tiempo.

Figura 7. Influencia de LST durante los 9 meses del periodo 2018 - 2019; analizando los valores digitales maximos y minimos. Figura a) NDVI/LST aumentó la fitosanidad en ESTE descendiendo en OESTE;

b) NDWI/LST aumentó el contenido de agua en Este y disminuyó en Oeste; c) SAVI/LST aumentó la erosion en Oeste y disminuyó en Este; y d) MSI/LST disminuyó el estrés hídrico en ambas orientaciones. Tamaño de pixel/celda es de 30×30m mejorado aplicando técnica de remuestreo de visualizacion interpolacion bilineal (proporcionando resultado de aspecto mas suavizado)

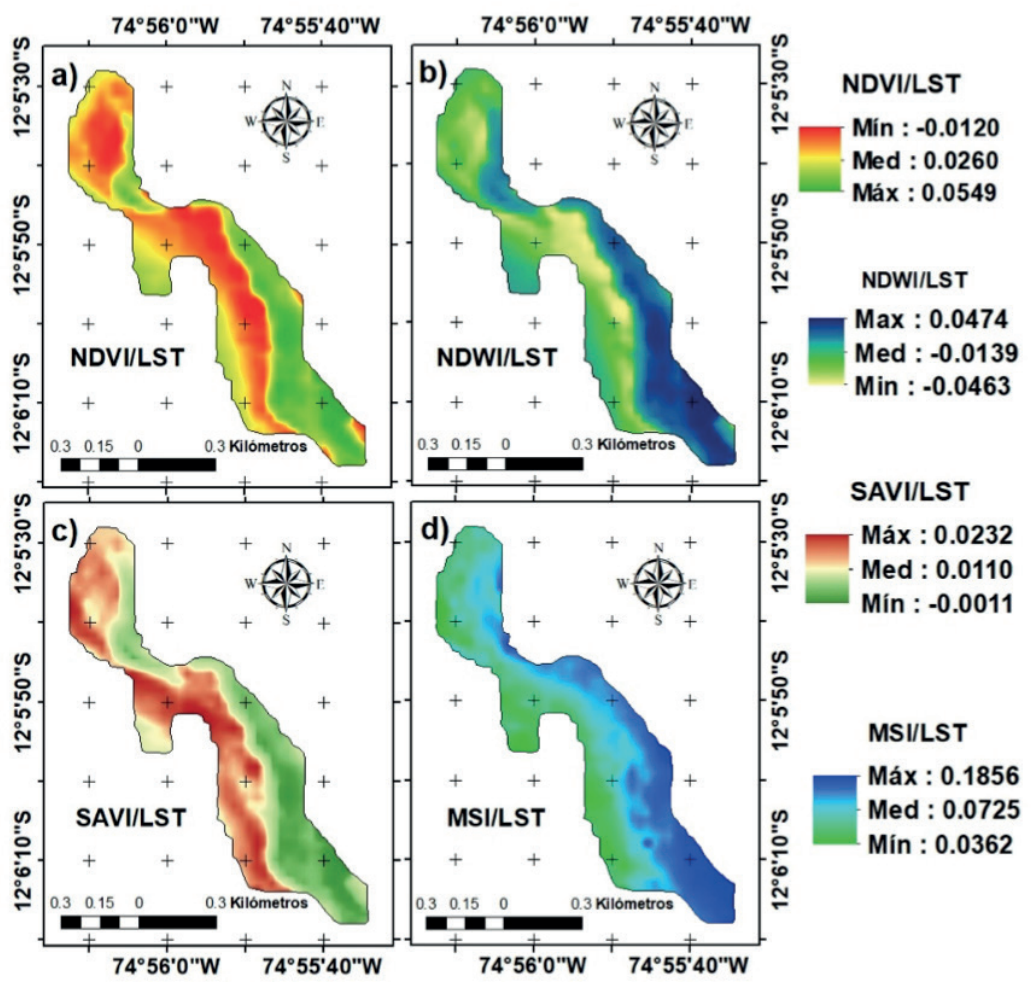




\section{Discusión}

La temperatura máxima que alcanzó este bosque es de $30.63^{\circ} \mathrm{C}$, validando así la investigación de Hoch y Körner (2005) de que la temperatura de estos bosques no supera de los $30^{\circ} \mathrm{C}$; y negando la investigación de Braun (1997) que afirma que la vegetación supera los $20^{\circ} \mathrm{C}$; esto ocurre debido a que existe espacios abiertos dentro del bosques en la orientación Oeste, permitiendo el ingreso de la luz del sol reportándose pequeños arboles de Polylepis, por desaparecer y emerger; afirmando así investigaciones de Braun (1997), Campomanes (2017) y Pacheco et al. (2018)), que la densidad de los bosques de Polylepis está directamente relacionado con la altitud y orientaciones.

Durante los 9 meses el NDVI indicó un estado saludable la vegetación con valores mínimo y máximos (-0.0778 - 0.6434), afirmando la descripción de Silva Laurentino (2014) y Weng et al. (2004) indicando un buen estado de sanidad del bosque (Silva Laurentino, 2014). El valor de -0.0778 pudo haber ocurrió debido a fenómenos meteorológicos dentro del bosque ya que esos bosques se encuentran en contacto con nubosidades (Hoch y Körner, 2005); el valor digital máximo del NDVI superó las investigaciones realizadas por Braun (1997), Contreras (2019) y Pacheco et al. (2018). Asimismo, los bosques se encuentran asociados a musgos y epifitas impidiendo la actividad fotosintética de las plantas. Durante un determinado mes el valor digital mínimo del NDVI fue de -0.3220 , indicando su estado enfermo, ya que existe actividades antropogénicas (como la quema y forestación) que interviene en el desarrollo de la planta o enfermedades transmitidas entre árbol a árbol, lo cual confirma las causas presentadas en investigaciones realizadas por Alshaikh (2015), Anbazhagan y Paramasivam (2016), Carvajal y Pabón (2014) y Hong et al. (2007). En otros lugares se ha observado que el valor mínimo es de -0.41 (Braun, 1997; Contreras, 2019), convirtiendo el bosque en un bajo estado fitosanitario, lo cual no ocurre precisamente en el bosque de Polylepis estudiado. El valor digital del NDWI mayor es 0.83179, indicando un alto contenido de agua sobre el bosque. Estos bosques requieren un buen nivel de humedad en el suelo (Almeida, 2015; Galvão et al., 2005), esto ocurre en la orientación Noreste, ya que la separación de árbol a árbol es menor a $5 \mathrm{~m}$ almacenando mayor cantidad de agua (Kessler, 2006) convirtiéndolos en resistentes a las sequias.

Otras investigaciones (Carvajal y Pabón, 2014; Contreras, 2019; Hoch y Körner, 2005; Hong et al., 2007) reportaron un NDWI menor a 0.42, en el cual el bosque no contiene más humedad de agua relacionado con la vegetación; la densidad de los bosques ayuda a conservar el agua superficial del suelo. Esto no ocurrió en la orientación Suroeste por la baja densidad de estos bosques. El SAVI, idea de Huete (1988), ayudó a identificar el problema de la erosión del suelo dentro del bosque, reportando un valor máximo de 0.5037, aunque no identificó el porcentaje de área erosionada como menciona Jepsen et al. (2009).

Considerando la orientación del bosque respecto al sol, se observó que existe un tramo de erosión en la orientación Suroeste, afirmando así la investigación por Campomanes (2017), Dourojeanni (2008), Mejia Rios (2014), Pacheco et al. (2018) y Braun (1997), ya que esto no ocurre en la orientación Este, donde existe la mayor densidad del bosque de Polylepis. La ecuación propuesta por Hardisky et al. (1983) determinó con éxito el estrés del bosque, encontrándose valor máximos de 1.7320; también podemos mencionar que la humedad aprovechable del suelo está directamente relacionada por el estrés hídrico de la planta y su temperatura, como lo afirma Silva Laurentino (2014) ya que no presentó un estrés hídrico muy intenso; también se observó que la mayor cantidad de estrés ocurre en la orientación Suroeste, donde existe una 
baja densidad de cobertura vegetal y el aumento de la temperatura, afirmando así su relación entre ambos (Hong et al., 2007); entonces, el estrés hídrico de la planta está relacionado con la orientación y densidad de vegetación.

La relación de la temperatura superficial terrestre y los 4 índices de vegetación está diferenciada por dos tipos de correlación: durante los 9 meses del periodo 2018 - 2019 y el promedio de las 9 imágenes satelitales clasificado en 20 valores naturales; existen distintas correlaciones entre el NDVI, NDWI, SAVI y MSI - LST ejecutado en distintos lugares donde la densidad y el tipo de bosque es diferente. No existen relaciones en bosques de un solo género, por ello existe variaciones de correlaciones. Analizando la correlación entre NDVI - LST realizadas por De Sousa y Júnior (2012) y Gonzaga (2014) se determinó correlaciones positivas $r=0.328$ y r = 0.74, muy por encima y totalmente diferenciado de correlación negativa $r=-0.0507$ realizado en el bosque de Polylepis, similares y muy por encima realizado por Alshaikh (2015), Anbazhagan y Paramasivam (2016), Carvajal y Pabón (2014) y Orhan et al. (2014) con $r=-0.181, r=-0.72, r=-0.9$ y $r=-0.98$ - 0.94; el análisis de correlación realizado en el bosque de Polylepis y diferenciado por fuentes bibliográficas afirma que cada área geográfica, densidad, grado de cobertura y fenómenos ambientales determina el tipo de correlación, sea positivo o negativo; si es positivo quiere decir que a mayor temperatura obtendrá un vigor de la biomasa fitosanidad del bosque. Si la correlación es negativa sucederá lo contrario. Ocurre algo totalmente diferente con la correlación promedio de las 9 imágenes satelitales clasificado en 20 valores naturales, donde la correlación obtuvo un $r=0.9959$ afirmando investigaciones realizadas por De Sousa y Júnior (2012), Gonzaga (2014). Estos valores naturales (Jenks) brindan un mejor distribución de los valores digitales del NDVI, creando así rango de clases entre mínimos y máximos; la correlación con los valores naturales de la temperatura determinarán una mejor correlación entre ambos conceptos, lo cual fue comprobado por investigadores como Alshaikh (2015) y Orhan et al. (2014). La diferencia de correlación entre NDWI - LST determinó un $r=-0.4325$ negativo en el bosque de Polylepis durante los 9 meses del periodo estudiando y totalmente diferente al promedio de las 9 imágenes satelitales clasificados en 20 valores, siendo casi similar a la investigación realizada por Carvajal y Pabón (2014) con un $r=-0.85$; se deduce que los valores naturales (Jenks) y durante un determinado tiempo la temperatura superficial influye en el contenido de humedad o contenido de agua en el suelo: a mayor temperatura el contenido de humedad en el bosque descenderá. En la relación entre SAVI - LST existen dos tipos de correlación: la positiva en el bosque de Polylepis durante los 9 meses del periodo con $r=0.1288$, se puede decir que es similar a la investigación realizada por De Sousa y Júnior (2012) con $r=0.27$, afirmando así que a mayor temperatura la cobertura vegetal interfiere a la erosión del suelo; todo lo opuesto ocurre con los valores naturales (Jenks), donde obtuvo una correlación negativa de $r=-0.9979$, siendo diferente a la correlación realizada por Gonzaga (2014) con $r=-0.342$, afirmando así que la temperatura superficial va aumentando a través del tiempo y que en la cobertura, suelo erosionado y densidad vegetal no existirá diferencia alguna. Esto pudo deberse a que este bosque no se encuentra en una intervención extrema o actividad antropogénica que altera el comportamiento y estado de la vegetación y que los bosques de Polylepis puede soportar el efecto de la temperatura y evitar la erosión del suelo. La correlación del MSI - LST que determina el estrés hídrico o déficit hídrico dentro del bosque ha sido influenciada por la temperatura; la relación entre ambos durante los 9 meses del periodo es un $r=0.5551$ siendo diferente al promedio de las 9 imágenes clasificadas en 20 valores naturales (Jenks) donde se obtuvo un $r=0.9903$; a medida que la temperatura aumenta o descienda el déficit o estrés hídrico lo hará de la misma manera; lo cual ocurre de manera to- 
talmente diferente en la investigación de Gonzaga (2014) con un r = -0.087 negativo; entonces el comportamiento de un área vegetal es totalmente diferente a su género, cualquier intervención y situación geográfico. Así mismo, las correlaciones fueron afirmadas mediante hipótesis de correlación y test de student, encontrándose diferencias entre la correlación entre los 9 meses del periodo estudiado y promedio de las 9 imágenes satelitales, evidenciando respectivamente que no existe correlación alguna entre los 9 meses del periodo y sí existe correlación mediante los valores naturales; esto pudo suceder debido que hubo cambios en valores naturales a través del tiempo, y los valores digitales del bosque permanecieron constantes.

La ecuación TVX afirma la influencia del LST sobre los índices de vegetación; comparada con otras fuentes de investigación, la única investigación que se aplica a los bosques de Polylepis es la de Goward et al. (1994), quien propuso la ecuación para determinar la influencia de la temperatura sobre el NDVI siempre en cuando existe relación entre ambas; por lo tanto, podemos afirmar que la ecuación determinó que existió la influencia de la temperatura sobre el bosque de Polylepis spp, la cual se aplicó a los 4 índices, y se evidencia en las orientaciones dentro del bosque; NDVI reportó un descenso del estado fitosanitario en la orientación Oeste y aumentó un buen estado fitosanitario en la orientación Este, de la misma manera en el NDWI descendió el contenido de agua dentro del bosque en la orientación Este y aumentó en la orientación Oeste; por otra parte, el SAVI reportó un deterioro de la vegetación en la orientación Oeste y no hubo efecto del LST en la orientación Este; y, por último, en el MSI el estrés dentro del bosque disminuyó en un estado medio en ambas orientaciones; también se observó que la LST crea un efecto de borde dentro del bosque la cual está diferenciado por los valores digitales de los índices de vegetación entre la densidad máxima y mínima del bosque; por lo cual podemos afirmar que es el intermediario para estimar mejor el estado de la vegetación.

\section{Conclusiones y recomendaciones}

LST mínimo/máximo del bosque de Polylepis spp 2018 - 2019 es $5.93^{\circ} \mathrm{C}-26.35^{\circ} \mathrm{C}$.

Durante 2018 - 2019 el bosque se encuentra en un buen estado fitosanitario y vigor de biomasa $(-0.0778-0.6434)$, contenido de humedad media-alta $(-0.6128-0.3057)$, con cobertura respecto al suelo, de erosión media-alta (0.0073 - 0.4089), estrés o déficit hídrico mediaalta (0.5565 - 1.3993), el bosque de Polylepis presenta diferentes tipos de valores digitales (de los índices de vegetación) debido a la orientación, distribución altitudinal, problemas atmosféricos/ecológicos, características edafológicos y asociaciones a otras plantas.

La correlación lineal de Karl Pearson durante los 9 meses del periodo 2018 y 2019 entre la temperatura superficial terrestre y los cuatro índices de vegetación presentó correlaciones medianamente bajas; el test de hipótesis t de student afirma que no existe correlación entre la temperatura y los índices de vegetación.

La correlación lineal promedio de las 9 imágenes satelitales clasificados en 20 Jenks Natural Breaks presentó correlación alta entre la temperatura y los cuatro índices de vegetación; el test de hipótesis t student determinó que sí existe relación lineal estadística alta entre los indices de vegetación y la temperatura superficial terrestre.

La ecuación TVX determinó la influencia del LST sobre los índices de vegetación, cambiando así su estado de vegetación en diferentes orientaciones como también crea un efecto de borde entre las zonas de mayor cobertura y menor densidad; diferenciando la sequía/efecto de la temperatura dentro del bosque de Polylepis spp. 
Se recomienda utilizar imágenes satelitales sin defectos meteorológicos (0 \% nubosidad) para obtener una mejor precisión y descripción de los valores digitales de los índices de vegetación, mejorando la calidad de la imagen y su respectivo procesamiento algebraico de bandas espectrales. Utilizar mayor cantidad de imágenes satelitales para obtener una mejor correlación y el test de hipótesis estadística durante diferentes meses. Aplicar todo tipo de índice de vegetación y correlacionar con la temperatura superficial terrestre para observar una mejor influencia de la temperatura sobre las coberturas vegetales y los estados de vegetación del bosque de Polylepis. Se recomienda utilizar los valores numéricos clasificados naturalmente (Jenks Natural Breaks) pues crea intervalos de clase basándose en su naturaleza numérica de valores digitales de cada índice de vegetación, el cual brinda una mejor correlación estadística, e interpretación de los valores naturales digitales de los índices de vegetación.

\section{Bibliografía}

Almeida, A. (2015). Procesamiento Digital De Imágenes Multiespectrales Landsat 8, Para Aplicaciones Agronómicas En La Subcuenca Del Río Guayllabamba (Universidad Central del Ecuador). Obtenido dehttp://www.dspace.uce.edu.ec/bitstream/25000/6489/3/T-UCE-0004-17.pdf

Alshaikh, A. (2015). Vegetation Cover Density and Land Surface Temperature Interrelationship Using Satellite Data, Case Study of Wadi Bisha, South KSA. Advances in Remote Sensing, 04(03), 248262. https://doi.org/10.4236/ars.2015.43020

Anandababu, D., Purushothaman, B. M., y Suresh Babu, S. (2018). Estimation of Land Surface Temperature using LANDSAT 8 Data. International Journal of Advance Research, 4(2), 177-186. Obtenido dewww.IJARIIT.com

Anbazhagan, S., y Paramasivam, C. R. (2016). Statistical Correlation between Land Surface Temperature (LST) and Vegetation Index (NDVI) using Multi-Temporal Landsat TM Data. International Journal of Advanced Earth Science and Engineering, 5(1), 333-346. https://doi.org/10.23953/cloud.ijaese.204

Braun, G. (1997). The Use of Digital Methods in Assessing Forest Patterns in an Andean Environment: The Polylepis Example. Mountain Research and Development, 17(3), 253. https://doi. org/10.2307/3673852

Bravo, F. (2017). Teledetección espacial (Primera Ed). Obtenido de https://acolita.com/wp-content/ uploads/2018/01/Teledeteccion_espacial_ArcGeek.pdf

Campomanes, Y. (2017). Escenario de distribución de los bosques de Polylepis al 2030 frente a los elementos climatológicos de Temperatura y Precipitación, en el distrito de Pomabamba -Ancash, utilizando Maxent y GIS, 2017. Universidad César Vallejo.

Carnahan, W. H., y Larson, R. C. (1990). An analysis of an urban heat sink. Remote Sensing of Environment, 33(1), 65-71. https://doi.org/10.1016/0034-4257(90)90056-R

Carvajal, A. F., y Pabón, J. D. (2014). Temperatura de la superficie terrestre en diferentes tipos de cobertura de la Región Andina Colombiana. Sociedade y Natureza, 26(1), 95-112. https://doi. org/10.1590/1982-451320140107

Contreras, O. (2019). Identificación De La Especie Polylepis reticulata Mediante Teledetección En Las Zonas Alto Andinas Del Ecuador. Escuela Superior Politécnica de Chimborazo.

De Sousa, S. B., y Júnior, L. G. F. (2012). Relação entre temperatura de superfície terrestre, índices espectrais e classes de cobertura da terra no município de Goiânia (GO). RA'E GA - O Espaco Geografico Em Analise, 26(26), 75-99. https://doi.org/10.5380/raega.v26i0.30151

Dourojeanni P. (2008). Distribución Y Conectividad De Bosques Alto Andinos (Polylepis) En La Cuenca Alta Del Río Pativilca (Pontificia Universidad Católica del Perú). Obtenido de http://tesis.pucp.edu. pe/repositorio/handle/20.500.12404/628 
Fjeldså, J. (1993). The avifauna of the polylepis woodlands of the Andean highlands: the efficiency of basing conservation priorities on patterns of endemisn. Bird Conservation International, 3, 37-55.

Galvão, L. S., Formaggio, A. R., y Tisot, D. A. (2005). Discrimination of sugarcane varieties in Southeastern Brazil with E0-1 Hyperion data. Remote Sensing of Environment, 94(4), 523-534. https://doi. org/10.1016/j.rse.2004.11.012

Gilabert, M. A., González-Piqueras, J., y García-Haro, J. (1997). Acerca de los índices de vegetación. Revista de Teledetección, Vol. 8(May 2014), 1-10. Obtenido de https://www.researchgate.net/publication/39195330_Acerca_de_los_indices_de_vegetacion

Gonzaga, C. (2014). Aplicación de Índices de Vegetación Derivados de Imágenes Satelitales Landsat 7 ETM + y ASTER para la Caracterización de la Cobertura Vegetal en la Zona Centro de la Provincia De Loja, Ecuador. Universidad Nacional de La Plata.

Gonzaga, C. (2015). Aplicación de índices de vegetación derivados de imágenes satelitales para análisis de coberturas vegetales en la provincia de Loja, Ecuador. Cedemaz, 5(1), 30-41. Obtenido de http://revistas.unl.edu.ec/index.php/cedamaz/article/view/43/41

Goward, S. N., Waring, R. H., Dye, D. G., Yang, J., Applications, S. E., May, N., ... Waring, R. H. (1994). Ecological Remote Sensing At Otter: Satellite Macroscale Observations '. 4(2), 322-343. https://doi. org/10.2307/1941937

Hardisky, M. A., Klemas, V., y Smart, R. M. (1983). The influence of soil salinity, growth form, and leaf moisture on the spectral radiance of Spartina alterniflora canopies. Photogrammetric Engineering y Remote Sensing, 49(1), 77-83. Obtenido dehttps://www.asprs.org/wp-content/uploads/ pers/1983journal/jan/1983_jan_77-83.pdf

Hoch, G., y Körner, C. (2005). Growth, demography and carbon relations of Polylepis trees at the world's highest treeline. Functional Ecology, 19(6), 941-951. https://doi.org/10.1111/j.13652435.2005.01040.x

Hong, S., Lakshmi, V., y Small, E. E. (2007). Relationship between vegetation biophysical properties and surface temperature using multisensor satellite data. Journal of Climate, 20(22), 5593-5606. https://doi.org/10.1175/2007JCLI1294.1

Huete, A. R. (1988). A Soil-Adjusted Vegetation Index (SAVI). Remote Sensing of Environment, 25(2), 295309. https://doi.org/10.1006/geno.1994.1397

Ito, E., Lim, S., Pol, S., Tith, B., Pith, P., Khorn, S., ... Araki, M. (2007). Use of ASTER Optical Indices to Estimate Spatial Variation in Tropical Seasonal Forests on the West Bank of the Mekong River, Cambodia. Forest Environments in the Mekong River Basin, 232-240. https://doi.org/10.1007/978-4-431-46503-4_21

Jepsen, J. U., Hagen, S. B., Høgda, K. A., Ims, R. A., Karlsen, S. R., Tømmervik, H., y Yoccoz, N. G. (2009). Monitoring the spatio-temporal dynamics of geometrid moth outbreaks in birch forest using MODIS-NDVI data. Remote Sensing of Environment, 113(9), 1939-1947. https://doi.org/10.1016/j. rse.2009.05.006

Kessler, M. (2006). Bosques de Polylepis. Botánica Económica de Los Andes Centrales, 110-120. Obtenido de http://www.beisa.dk/Publications/BEISA Book pdfer/Capitulo 07.pdf

Mejia Rios, A. A. (2014). Metodologá para la cartografia de bosques del genero Polylepis, aplicando Geomatica (Universidad Nacional Agraria la Molina).

Muñoz, P. (2013). Apuntes de Teledetección: Índices de vegetación. In Centro de información de recursos Naturales (Pimera Edi). https://doi.org/http://bibliotecadigital.ciren.cl/bitstream/handle/123456789/26389/Tema \%20Indices \%20de \%20vegetaci \%C3 \%B3n \%2C \%20Pedro \%20Mu \%C3 \%B10z \%20A.pdf?sequence=1yisAllowed=y

Orhan, O., Ekercin, S., y Dadaser-Celik, F. (2014). Use of Landsat land surface temperature and vegetation indices for monitoring drought in the Salt Lake Basin Area, Turkey. The Scientific World Journal, 2014(December), 13. https://doi.org/10.1155/2014/142939 
Pacheco, M., Franco, P., Cáceres, C., Navarro, M., y Jove, C. (2018). Aplicación De Técnicas SIG Para La Cobertura Superficial Y Distribución Del Bosque De Polylepis En La Zona Andina De Moquegua 2018. 17(2), 26-32. https://doi.org/10.33326/26176033.2018.23.753

Rock, B. N., Vogelmann, J. E., Williams, D. L., Vogelmann, A. F., y Hoshizaki, T. (1986). Remote Detection of Forest Damage. BioScience, 36(7), 439-445. https://doi.org/10.2307/1310339

Rouse, J. W., Hass, R. H., Schell, J. A., y Deering, D. W. (1973). Monitoring vegetation systems in the great plains with ERTS. Third Earth Resources Technology Satellite (ERTS) Symposium, 1, 309-317. https://doi.org/citeulike-article-id:12009708

Segovia-Salcedo, M., Domic, A., Boza, T., y Kessler, M. (2018). Situación taxonómica de las especies del género Polylepis. Implicancias para los estudios ecológicos, la conservación y la restauración de sus bosques. Ecología Austral, 28, 188-201. https://doi.org/https://doi.org/10.25260/ EA.18.28.1.1.527

Silva Laurentino, M. L. (2014). Aplicaciones de la teledetección en el análisis de daños en masas de coníferas en la provincia de Burgos - España (Universidad de Valladolid). Obtenido de https://uvadoc. uva.es/bitstream/10324/6649/1/TFM-L187.pdf

Smith, M. J. de, Goodchild, M. F., y Longley, P. A. (2018). Geospatial Analysis A Comprehensive Guide to Principles Techniques and Software Tools (Sixth Edit). https://doi.org/www.spatialanalysisonline.com

Speranza, F. C., y Zerda, H. R. (2002). Potencialidad De Los Índices De Vegetación Para La Discriminación De Coberturas Forestales. (1), 1-10. Obtenido de https://www.academia.edu/13450382/P0TENCIALIDAD_DE_LOS_INDICES_DE_VEGETACIÓN_PARA_LA_DISCRIMINACIÓN_DE_COBERTURAS_FORESTALES

Stimson, H. C., Breshears, D. D., Ustin, S. L., y Kefauver, S. C. (2005). Spectral sensing of foliar water conditions in two co-occurring conifer species: Pinus edulis and Juniperus monosperma. Remote Sensing of Environment, 96(1), 108-118. https://doi.org/10.1016/j.rse.2004.12.007

USGS. (2019). LANDSAT 8 (L8) DATA USERS HANDBOOK. In USGS (Ed.), Department of the Interior, U.S. Geological Survey (Version 4., Vol. 4). Obtenido de https://prd-wret.s3-us-west-2.amazonaws. com/assets/palladium/production/atoms/files/LSDS-1574_L8_Data_Users_Handbook_v4.0.pdf

Weng, Q., Lu, D., y Schubring, J. (2004). Estimation of land surface temperature-vegetation abundance relationship for urban heat island studies. Remote Sensing of Environment, 89(4), 467-483. https://doi.org/10.1016/j.rse.2003.11.005

Zutta, B. R., Rundel, P. W., Saatchi, S., Casana, J. D., Gauthier, P., Soto, A., .. Buermann, W. (2012). Prediciendo la distribución de Polylepis: bosques Andinos vulnerables y cada vez más importantes. Revista Peruana de Biologia, 19(2), 205-212. https://doi.org/10.15381/rpb.v19i2.849 